\title{
DOCUMENTO SUPLEMENTAR
}

Miguel Covarrubias e Andrés Guevara: a influência do cubismo na ilustração editorial do início do século $\mathrm{XX}$

1. Caricatura de Giulio Gatti-Casazza feita por Covarrubias para a edição de estréia da The New Yorker, 1925.

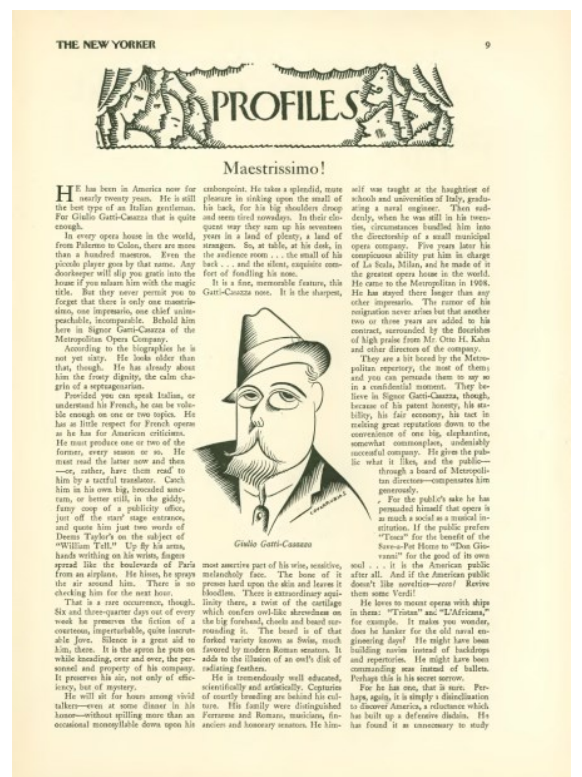

Fonte: The Complete New Yorker. Introdução de David Remnick. New York: Random House, 2005, DVD “1925-1936”.

2. Trabalho de Covarrubias: caricatura de Frank Conroy e Ethel Barrymore, The New Yorker, 1926.

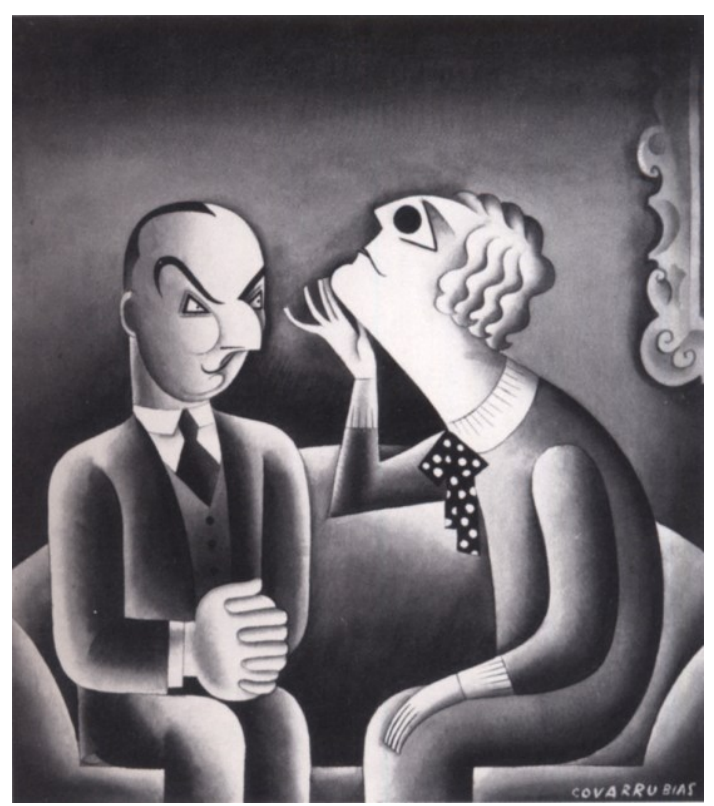

Fonte: HEINZELMAN, Kurt (org.). The Covarrubias Circle. Austin: University of Texas Press, 2004, p. 69. 
3. Miguel Covarrubias: caricatura de Paul Whiteman, 1924.

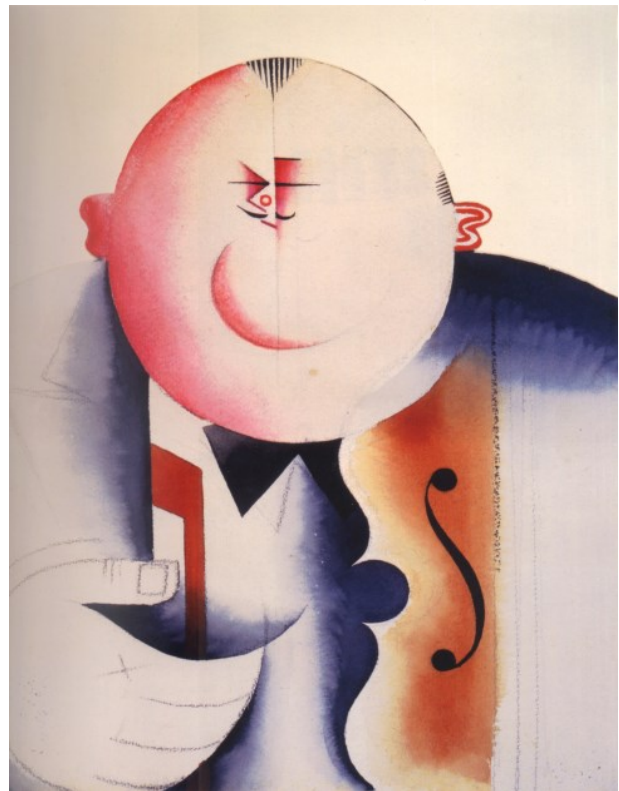

Fonte: HEINZELMAN, Kurt (org.). The Covarrubias Circle. Austin: University of Texas Press, 2004, p. 67.

4. Miguel Covarrubias: “Black woman”, 1927.

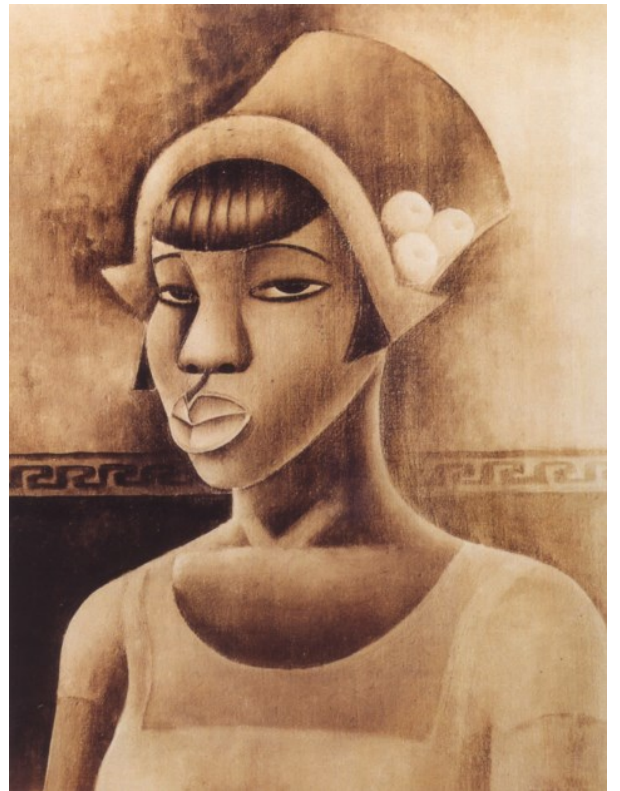

Fonte: AYALA, Eva; COVARRUBIAS, Miguel; HERNANDEZ, Selva; RIVERA, Juan Rafael. Miguel Covarrubias: 4 Visions. Cidade do México: Editorial RM, 2007, p. 73. 
5. Desenho do livro "Método de dibujo. Tradición, resurgimiento y evolución del arte mexicano", com ilustrações que podem ser de Covarrubias ou de Adolfo Best Maugard, 1923.

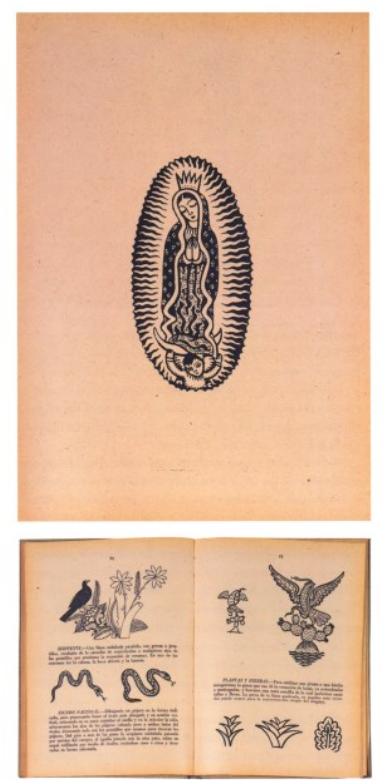

Fonte: AYALA, Eva; COVARRUBIAS, Miguel; HERNANDEZ, Selva; RIVERA, Juan Rafael. Miguel Covarrubias: 4 Visions. Cidade do México: Editorial RM, 2007, p. 20.

6. Andrés Guevara: caricatura de Sergei Voronov, 1928.

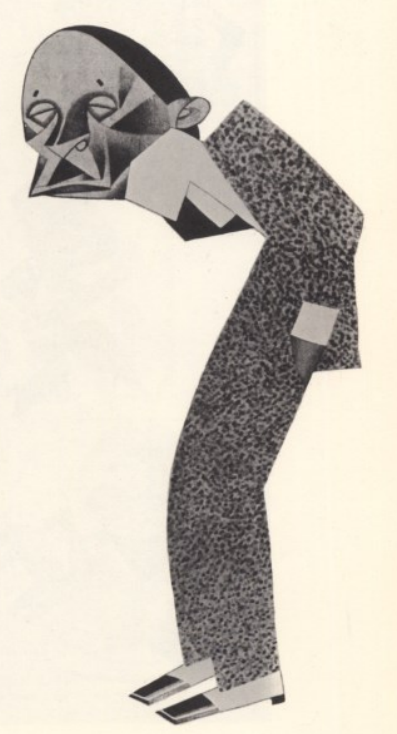

Fonte: LOREDANO, Cássio. Guevara e Figueroa. Rio de Janeiro: FUNARTE, 1988, p. 57. 
7. Covarrubias: caricatura de Van Vechten publicada no livro "Meaning No Offense", 1928.

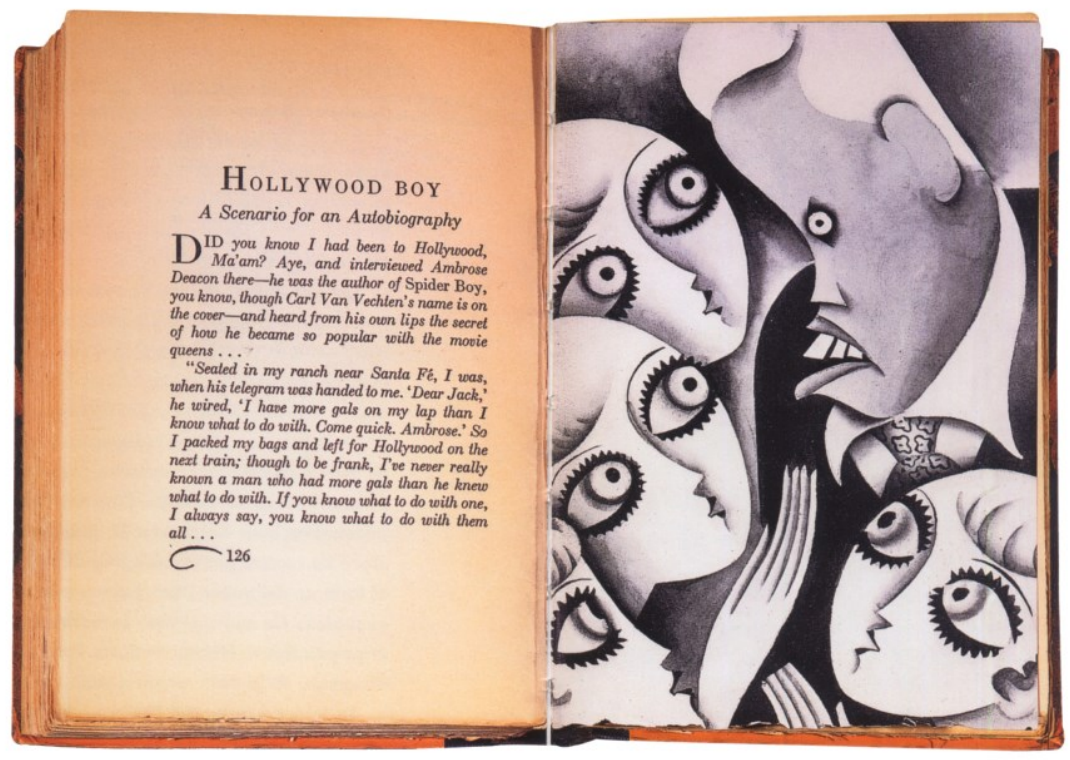

Fonte: AYALA, Eva; COVARRUBIAS, Miguel; HERNANDEZ, Selva; RIVERA, Juan Rafael. Miguel Covarrubias: 4 Visions. Cidade do México: Editorial RM, 2007, p.30-31.

8. Andrés Guevara: caricatura de Prado Júnior para a capa de O Malho, 1929.

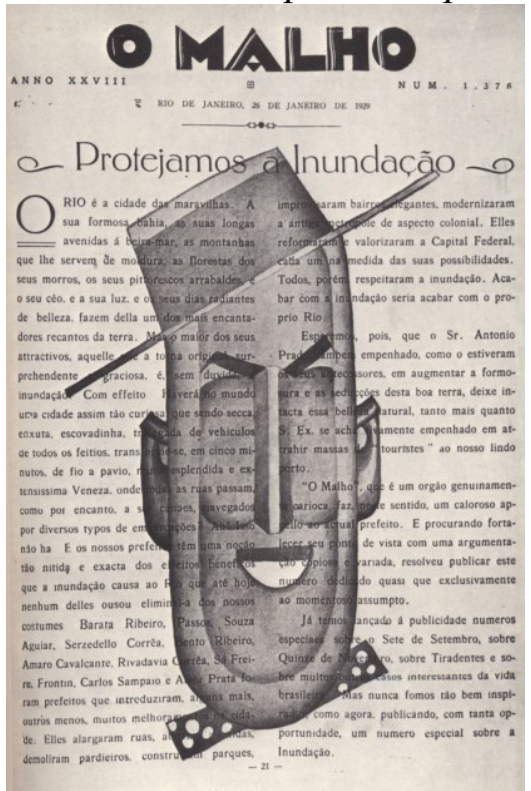

Fonte: LOREDANO, Cássio. Guevara e Figueroa. Rio de Janeiro: FUNARTE, 1988, p. 61.

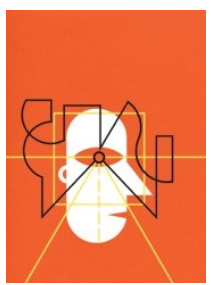

